\section{Digital Planning on Guided Endodontics Technology}

Daniel A Decurcio (D1, Mike R Bueno (1)2, Julio A Silva (D1, Marco A Zaiden Loureiro (D1, Manoel Damião Sousa-Neto [133, Carlos Estrela (D1.

The aim of this review is to discuss the digital planning and the use of guided technology in Endodontics. The complexity of the root canals anatomy and the challenges in the microorganism's control represent risk factors for failure after the infected root canal's treatment. Scientific improvements associated with technological advances have enabled better predictability of therapeutic procedures results. The development of efficient and modern devices provided safer root canal treatments, with shorter clinical visits and greater patient comfort. Digital endodontics incorporated different tools and developed its own, advancing even further in resolving complex cases. The faithful copy of the internal anatomy provided by the advancement of CBCT devices and software's, associated with the digital resources of 3D planning and printing, enabled the advent of guided endodontics. This technique is used at different stages of endodontic treatment, with specific indications and greater result predictability. Therefore, this study critically reviewed the potential clinical application of this guided access technique, and the operative steps for its safe performance in managing complex endodontic cases. The main indications are accessing calcified root canals, performing endodontic surgeries in difficult access areas, removing fiberglass posts, and accessing teeth with developmental anomalies. In summary, guided endodontics has been a precise strategy, effective, safe, and clinically applicable. This procedure represents incorporating technological resources and digital planning in the Endodontist clinical practice, increasing predictability to complex cases.
'Department of Stomatology Sciences, School of Dentistry, Federal University of Goiás, Goiânia, Brazil;

${ }^{2}$ Department of Radiology, School of Dentistry, University of Cuiabá, Cuiabá, MT, Brazil;

${ }^{3}$ Department of Endodontics, School of Dentistry, University of São Paulo, Ribeirão Preto, SP, Brazil

Correspondence: Professor Carlos Estrela School of Dentistry, Federal University of Goiás Setor Universitário, 74605-220 Goiânia, G0, Brazil. Phone: +55-62-3209-6254.

e-mail: estrela3@terra.com.br

Key Words: Endodontics, root canal, guided endodontics, cone-beam computed tomography, software, technology.

\title{
Introduction
}

The root canal's anatomy complexity represents one of the eminent challenges facing endodontists in clinical practice (1-3). Parallel to this aspect, the maintenance of microorganisms after root canal treatment constitutes the main cause of failure. In this sense, scientific improvements associated with technological advances have better predictability of therapeutic procedures results (4).

The technological revolution has been a constant in the health area, with fast advances and geometric progression. The development of efficient and modern devices provided safer root canal treatments, with shorter visits and greater patient comfort. Safety in automated root canal instrumentation with nickel-titanium files (5-7), precision in determining the working length with electronic apex locators (8), the versatility of the ultrasonic device in various clinical stages (9), the better visualization of the operative field with magnification (10) and the most accurate diagnoses with the use of cone-beam computed tomography (CBCT) (11-13) highlight some of these technological advances that have boosted endodontics and increased the quality perspective of results.

These devices do not reduce the endodontist's responsibility, competence, and skill in clinical management. The conjunction between current scientific knowledge and the development of clinical skills is essential for more accurate diagnoses, more assertive behavior, and better prognoses. Professionals must employ the best tools available, be open to developments in their area of expertise, and not be tied to obsolete techniques or materials. Incorporating new technologies in clinical practice may lead to greater predictability and safety treatments $(12,14)$.

Digital dentistry has become a reality of clinical procedures and has been widely explored by oral rehabilitation, implantology, orthodontics, oral surgery, among others (15). The possibility of faithfully copying the dental or facial anatomy and transferring this model to the virtual environment stimulated a new moment, the era of digital planning. The development of specific software for this purpose made it possible to virtually plan the clinical stages, evaluating possible errors or accurately predicting the amount of wear in tooth preparation, direction, and length of an implant, tooth movement pattern, etc. 
Thus, treatment by trial and operative procedures error may be avoided, and it is planned more efficiently and with less clinical time with the patient.

Digital endodontics incorporated different tools and developed its own, further advancing in resolving complex cases (16). The faithful copy of the internal anatomy provided by the advancement of CBCT devices and software's, associated with the digital resources of 3D planning and printing, enabled the advent of guided endodontics. This technique is used at different stages of root canal treatment, with specific indications and greater results predictability. Therefore, this study critically reviewed the potential of guided endodontics application and managing complex endodontic cases. Based on this perspective, the essential clinical factors for the digital planning of endodontic guide technology will be addressed.

\section{Guided Endodontics Technology}

Digital Resources in Endodontics

Cone-beam computed tomography (CBCT) is the basis of digital planning in Endodontics. Endodontics bases its planning on information obtained from meticulous navigation through CBCT images, which provide details of the internal anatomy of the teeth and adjacent structures. On the other hand, digital planning applied to oral rehabilitation is primarily based on the images obtained by intraoral scanners, which copy the external surface of teeth and adjacent periodontal tissues. The structures of interest for endodontics have tiny dimensions, representing a significant challenge for the endodontist in detecting root ramifications, fractures, perforations and determining different levels of obliteration and thickness of root canal walls. This complex condition in visualizing the endodontic microanatomy requires high-resolution imaging exams (13).

The CBCT image's quality is determined by the characteristics of the tomograph (the device), acquisition settings, patient stability and by the software for acquiring and running the images. In diagnosing endodontic microanatomy, it is more important to prioritize image acquisition using highresolution CT scanners with a better focal point than the equipment capable of acquiring large volumes and recording larger areas. The quantity and density of materials present in the patient's mouth can also influence image quality, as dense materials can produce artifacts that overlay essential details. This inconvenience caused by artifacts can be minimized by using advanced image software. Software such as e-Vol DX (CDT Software, São José dos Campos, Brazil) can receive the standard image acquisition file generated by most CT scanners, DICOM (Digital Imaging and Communications in Medicine), and apply artifact reduction filters (BAR - Blooming Artifact Reduction), filters for the expansion of root canal images while preserving the details ( $\mathrm{ACl}$ - Accessory Canal Identification/Navigation); in addition to 3D reconstruction techniques capable of generating photorealistic images (Cinematic Rendering). These tools that increase the quality of the $\mathrm{CBCT}$ image improve the diagnostic capacity and consequently positively impact clinical decision-making $(11,14)$.

Digital planning software was also fundamental for advancing digital endodontics towards developing guides applied to our area. Digital planning software imports DICOM files from CBCT exams and uses them as parameters to outline guides with computer-aided design (CAD - Computer-Aided Design) tools. In modeling the guides, current digital planning software needs to synchronize the DICOM file with the digital file of a model of the patient's arch in STL (Standard Tesselation Language) format. The digital model is obtained with intraoral scanning equipment (15).

The 3D printing technology (Stereolithography technique) allows the production of endodontic guides. The three-dimensional design of the guide developed by the digital planning software is also exported in STL format. Before 3D printing, the planned STL needs to be prepared to transform the guide's STL file into a sequence of numerous layers or slices. The smaller the thickness of the slices, the greater the reliability of the printed guide; on the other hand, the more time will be spent in the printing process. Currently, endodontic guides are printed in light-curing liquid resin with direct light processing technology (DLP - Direct Light Processing) due to the better cost-benefit ratio (17).

\section{Guided Endodontics Indications}

Guided endodontics has been indicated in different clinical situations (Figure 1). A better understanding of its characteristics and the exploration of digital resources in endodontics provided greater clinical applicability. Indications should not be interpreted as a specific convenience resource and facilitator for professionals with less clinical experience and/or who do not use the appropriate technology for complex endodontic treatments but rather as an additional tool to the endodontist's arsenal (18). 


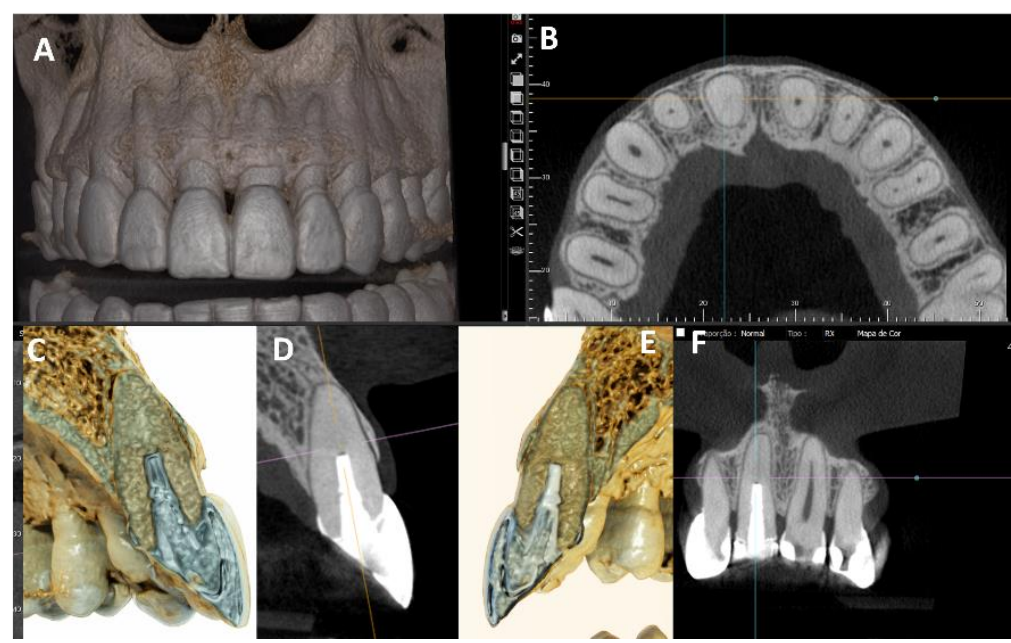

Figure 1 - CBCT images of a clinical case with an indication for Guided Endodontics (A). The patient had a clinical diagnosis of mobility of the crown of tooth 11 and fracture of the fiberglass intraradicular post. The axial view at the apical third (B) reveals an obliteration aspect of the root canal. The sagittal (C$\mathrm{E}$ ) and coronal (F) views show the longitudinal extension of the fiberglass post up to the middle third of the root and the absence of a root canal in the middle and cervical thirds.

The initial indication of guided access is related to calcified canals (19-21). Root canal obliteration may reach only the cervical third of the root or extend to the middle or apical third. The cause may be associated with several factors, such as a consequence of traumatic dental injury, after orthodontic treatment, response to pulp injuries such as caries or restorative materials, or even in elderly patients (22). In these cases, root canal treatment becomes necessary when calcification is related to periapical pathologies $(16,19,20)$.

Coronary access represents the most challenging operative step in a calcified tooth, making it difficult to maintain the correct trepanation direction when it extends mainly to the middle and apical thirds. Even for experienced endodontists, it can result in deviations or perforations, increasing the chances of failure (16). In this sense, using the guided technique provides greater safety, greater predictability, less volume of dental tissue removed, and shorter clinical time with the patient (23-25).

Guided endodontics has also been indicated in cases of endodontic surgery (26-28). A guide for surgical access is necessary, with less removal of bone tissue and better location of the lesion region and dental apex $(27,28)$. Furthermore, these guided procedures reduce the risk of trans and post-surgical complications, such as bleeding or damage to neighboring anatomical structures. In addition to these factors, it leads to a shorter healing time and a better prognosis $(26,27)$.

Challenging cases related to surgical access and proximity to noble anatomical structures can be better performed using prototype guides. Benjamin et al. (28) reported 3 cases with surgical guides used in a targeted endodontic microsurgery approach, illustrating the diagnostic value of CBCT imaging for detecting neurovascular bundles and the use of the guides to mitigate the risk of injury to these important structures. Giacomo et al. (29) demonstrated the use of guided access in surgeries related to the palatal root of maxillary second molar, fused roots of a maxillary first molar, and a mandibular second premolar with apical proximity to the mental foramen. In all reported cases, guides promoted an accurate osteotomy and apicectomy related to angulation, diameter, and extension.

The use of fiberglass posts in oral rehabilitation has become a reality in recent years. However, when necessary, its removal represents a great challenge for dentists and may lead to root deviations or perforations, propagation of cracks, or even fractures (30). Thus, virtual planning and printing of guides have contributed to greater safety in this procedure and reduced clinical time, bringing greater patient comfort and reducing professional stress (30-33).

Experienced endodontists use various resources for removing fiberglass posts, such as operative microscopy and ultrasonic. However, a recent study (34) that evaluated dentin loss and deviations in the root canal path compared guided access with magnification and ultrasonic resources showed favorable results for the guided technique. A smaller amount of worn dentin was observed, with less deviation 
from the original path, and less operative time in guided endodontics, which resulted in greater predictability of the procedure.

Access in teeth with developmental anomalies has also been one of the indications for using endodontic guides (35-37). Dental malformations, such as dens invaginatus, can represent a complicating issue when endodontic treatment is required. Thus, the association of a correct diagnosis of the pulpal/periapical condition with three-dimensional imaging exams leads to more assertive treatments. However, these anomalies make proper access difficult, increasing the possibility of excessive tooth wear, error in the entry direction, or even root perforations. In this sense, guided access has been a viable and predictable alternative.

An important topic to be raised refers to teeth with cracks, root fractures or resorptions. For accurate planning, a CBCT with high spatial resolution must be carefully analyzed by a well-trained professional, tracking the tooth thoroughly to verify the viability of the tooth for the application of the guided technique.

\section{Planning and Digital Flow of Guided Endodontics}

The guided endodontics technique can be divided into:

1 - A laboratory phase for production of the endodontic guide, in which most processes are performed in the absence of the patient, with the aid of digital tools;

2 - A clinical phase of application of the guide in operative procedures.

The Digital Flow of Guided Endodontics follows the same sequence of processes performed in the Digital Flow of Implantology for guided surgical procedures in implant installation. Once the indication for the use of an endodontic guide is stated, the professional must check if the patient has both the CBCT exam in the region of interest and the patient's arch model in digital format. Since the Digital Flow starts with the acquisition of DICOM and STL files, and if the patient has performed this acquisition recently, without further dental interventions that may have changed the internal dental anatomy or the surface of the oral tissues (teeth/periodontium), these files can be assessed. If the patient does not have them or has any of these files in poor quality, a new request must be made. The DICOM file will be obtained by requesting the CBCT exam, and the STL file will be obtained by scanning the intraoral arch of the patient.

After acquiring the DICOM and STL files, the planning of the endodontic guide is carried out by Digital Planning Centers (Planning Centers) or trained professionals, using specific software for planning surgical guides. These planning tools were developed to guide the installation of implants and not wear and tear on the internal part of the tooth. Therefore, sometimes, the Guided Endodontics technique may be contraindicated during the planning phase due to the scarcity of resources applied to the reduced dimensions of the Endodontics area of operation. In addition to the dimensions of wear length and diameter, the direction and region to be worn by the drill must be carefully planned. Trajectories that promote wear of critical anatomical structures for tooth longevity, such as incisal edge, enamel bridges, and cusp tips, should be avoided. Once the wear length and trajectory planning have been defined, it is essential to estimate the thickness of tooth tissue after the guided procedure has been performed. Plans should not project wear at a distance of less than $1 \mathrm{~mm}$ from the root surface in contact with the periodontal ligament to avoid perforation accidents. Although guided wear is predictable, it is considered an average of deviations of up to $0.4 \mathrm{~mm}$ at the end of the drill in guided wear to the apical third of the root (38). Deviations are minimized by rigorous planning and guide printing. The more adapted the occlusal surface of the teeth, the greater the stability of the guide and the lesser the risk of deviation during the wearing procedure. Inspection windows are planned in different parts of the guide to verify adaptation in the operative phase.

Clinical situations unfavorable to the stability of the guides require the planning of resources that limit their mobility. For example, guides supported by a reduced number of teeth or the absence of teeth adjacent to the region of the guided procedure are unfavorable factors for its stability. In these situations, we must plan the stabilization of the guide with fixation pins. The use of metal rings is also a feature that helps in the stability of guided wear. According to the planned path, the metal ring can restrict the drill's movement in a linear direction in the crown/apex direction.

Once the endodontic guide project is completed, a detailed Virtual Planning Report must be sent to the dentist responsible for the case, for analysis and approval. Only after approval, the STL file of the guide design is sent for 3D printing. Finally, endodontic guides are printed on resins that can be autoclaved. 


\section{Clinical operative steps}

To be successful in guided endodontic accesses, it is essential that all previous laboratory steps have been fulfilled. Furthermore, according to the topics discussed above, the technological resources for the diagnosis and planning of the digital flow are of fundamental importance to provide a correct indication of the use of guides, as well as the materialization of this resource. Therefore, in this topic, the approach will be step-by-step to facilitate understanding, what the clinician must establish from the arrival of the printed guide to the guided access through a clinical case of root canal obliteration with previous nonsuccess access associated with apical periodontitis (Figure 2A-C).

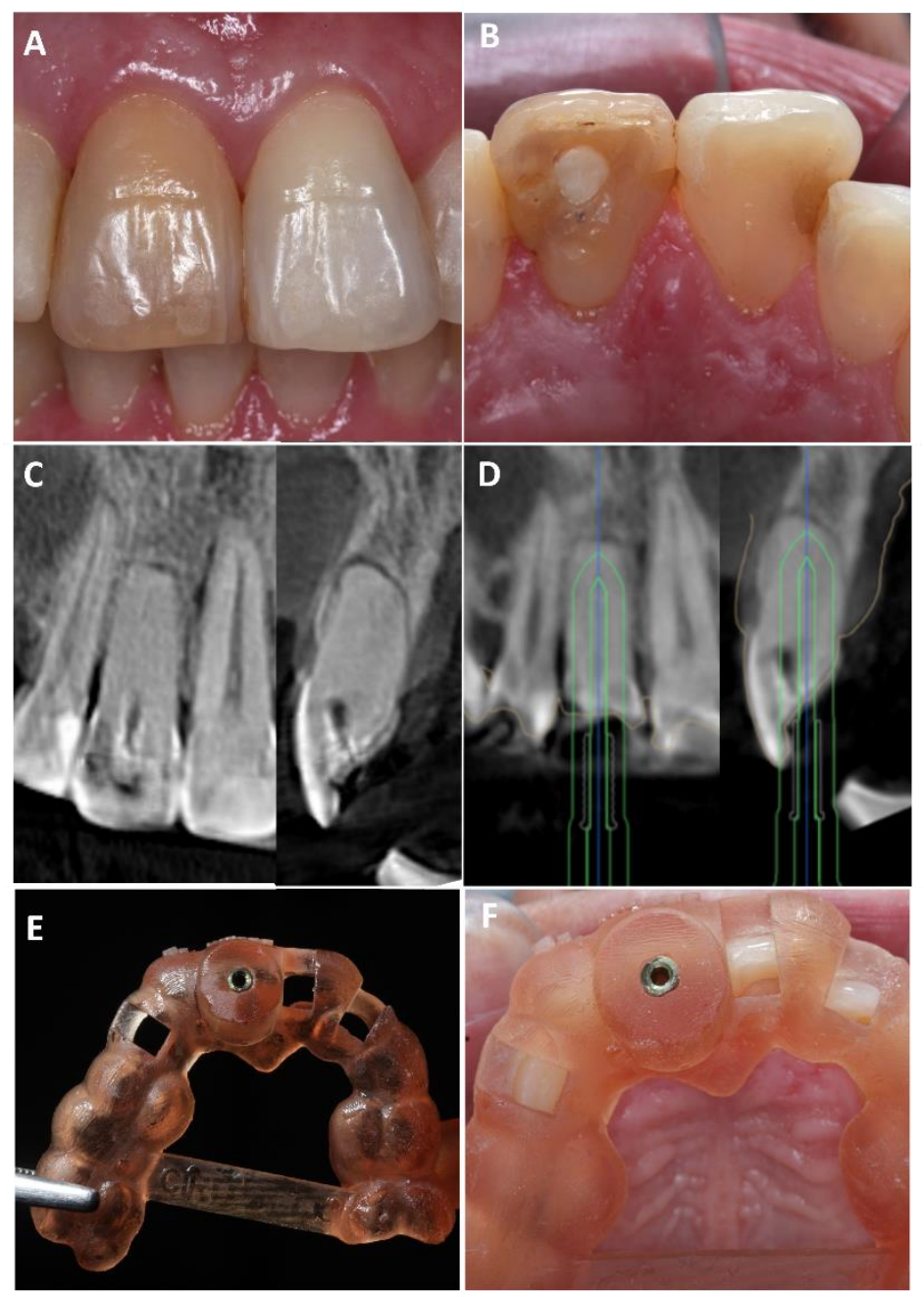

Figure 2 - Initial clinical appearance: frontal view (A) and occlusal view (B) of the maxillary central incisors. Tooth 11 has a darkening of the entire coronary structure and glass-ionomer cement restoration in the center of the palatal surface. CBCT images: coronal (C1) and sagittal (C2) sections show canal calcification of tooth 11 and the incorrect course of the first attempt at endodontic access, starting at the center of the palatal surface and towards the buccal surface. In D1 and D2, the access path outlined by the digital planning can be seen. Endodontic Guide: (E) occlusal view shows support base from tooth 16 to tooth 25 , and a stabilization bar connecting teeth 15 and 25, (F) shows metallic ring installed in the access guide and inspection windows for verification of guide adaptation.

Endodontic guides are designed and printed in digital planning centers and delivered to the clinician ready to use. However, in addition to participating in the guide planning, the Endodontist is responsible for checking various aspects that may interfere with the final result of the treatment (Figure 2D). A virtual planning report is sent by the Planning Centers with information about the intraoral scan, the drill trajectory, guide length on adjacent teeth, and also about the presence and position of visual inspection windows. Thus, possible distortions or failures in printing the guide should be verified through the final report, such as incorrect positioning of the visual inspection windows, presence or absence of a metal ring, and the extension and support of the guide different from what was planned. 
After confirming the quality of the printed guide (Figure 2E), the tests are carried out in the mouth to verify its perfect adaptation and stability (Figure 2F). As discussed in the Planning and digital flow for Guided Endodontics, planning can be carried out for guides with support only on adjacent teeth or guides with support on adjacent teeth and fixed in bone $(16,19,21)$. However, regardless of the choice of fixation on bone or not, the visual inspection windows are an essential indicator of the perfect adaptation of the guide (Figure 2F). They indicate that the planning and printing were carried out correctly.

Currently, Endodontics uses instruments and software for planning guided surgery for implant dentistry and, therefore, the drill used for the vast majority of guided approaches is $1.3 \mathrm{~mm}$ in diameter (Neodent, Curitiba, Brazil). Unfortunately, this drill does not have cutting power in enamel. Therefore, it is necessary to perform slight prior wear with diamond drills in the enamel region so that the implant drill works primarily on dentin. Then, a marking is made with the guide already positioned to carry out the initial wear, seeking the point of choice.

Following operative stages, the next step is to perform the guided endodontic approach (Figure $3 \mathrm{~A}-\mathrm{C})$. For this, an electric motor in continuous rotation with a speed set at $800 \mathrm{RPM}$ and a torque of $4.0 \mathrm{Ncm}$ is required. After re-verifying the perfect position of the guide, it must be stabilized with manual support and constant irrigation. Finally, the drill must go in until it taps the ring's base, which is the depth reference, and it must go through until reaching the planned point.

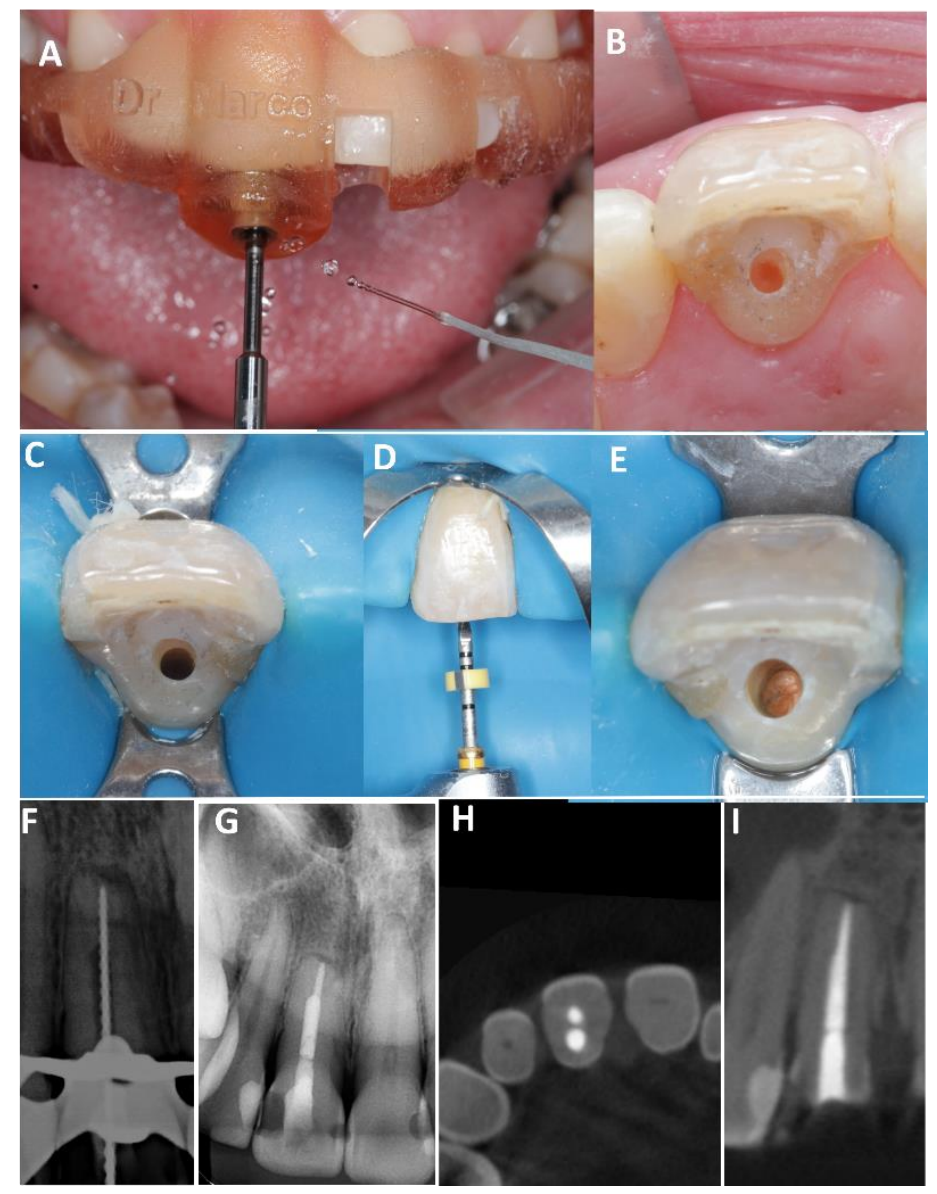

Figure 3 - Endodontic Access: Front view (A) - Endodontic guide and drill in position, under irrigation with saline solution; Occlusal view (B) verification of initial wear following virtual planning. Endodontic Treatment: (C) Endodontic access final aspect in occlusal view, (D) Frontal view with X5-Protaper Next file in root canal position, (E) occlusal view of the obturated canal. Imaging examinations: (F) radiograph with a file at the working length after root canal preparation, $(G)$ periapical radiograph of the filled canal and the restored tooth; and axial $(\mathrm{H})$ and coronal (I) sections after obturation and final coronary restoration in cone-beam computed tomography exams.

The irrigation process must be continuous and carried out towards the inside of the guide. At each advancement of $3 \mathrm{~mm}$, the path's interior is created, and the end of the drill is washed, removing all the 
excess of adhered dentin. As soon as the drill touches the ring base, the guided access is completed, and the next step should be taken, which is the mapping and location of the calcified canal with smallcaliber files.

In the clinical case in question, absolute isolation was performed, and access to the calcified root canal was reached with a K-file n.10 file (Dentsply/Maillefer, Ballaigues, Switzerland). Then, the root canal treatment was carried out following the entire protocol of root canal preparation, enhancement of the irrigating solution, use of intracanal medication based on calcium hydroxide paste, and subsequently filled and restored with composite resin (Figure 3D-I). After the case report conclusion, a new CBCT acquisition was performed, which showed the correct path of the drill in the guided endodontic access, without excessive wear and deviation, which provided free access to the root canal (Figure 4). This illustrative clinical case aimed to demonstrate the application protocol and the accuracy of Guided Endodontics in solving calcified canals, providing greater safety to the operator.
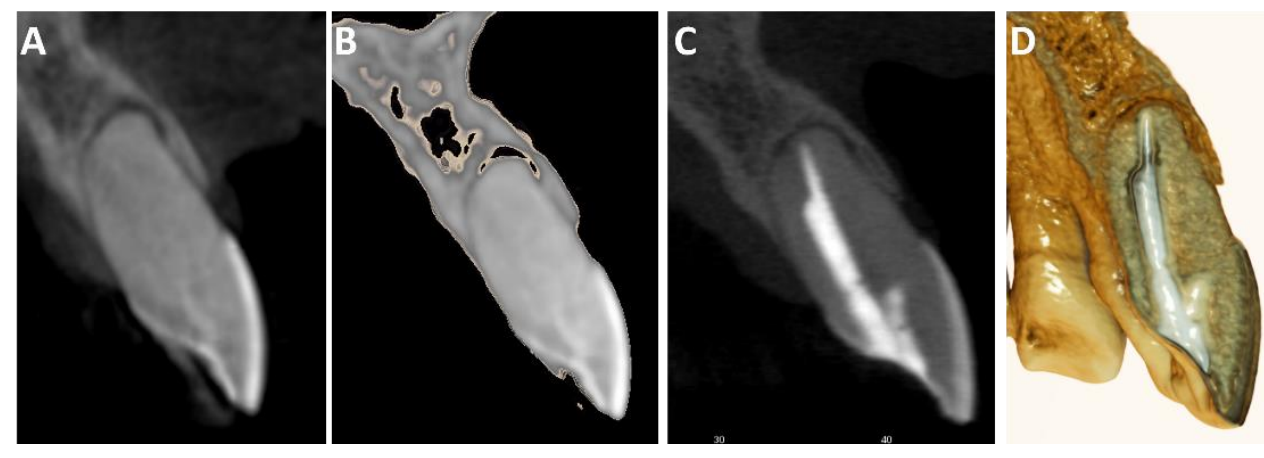

Figure 4 - CBCT images before $(A, B)$ and after $(C, D)$ the guided access.

\section{Discussion}

Guided Endodontics is a technique in constant evolution, reflecting the fast change that modern endodontics is witnessing. Technological advances provide tools that are increasingly more adequate and precise for Endodontics, evolving towards a more accurate technique with lower cost and greater reach to the clinician. Even so, it has limitations, and these must be evaluated before planning and executing it.

The complex anatomy of root canals, despite involving the main indications for guided planning, may also represent some limitations of the technique. Guided access is only possible in the straight region of the root canal and becomes imprecise in curvature areas. In this sense, the planning must be evaluated well, directing the wear and the drills only to the straight portion and avoiding bending. Another aspect related to dental anatomy refers to the root diameter. The different root configurations (3) in the various dental groups may reflect in roots with minimal thickness in the mesiodistal and/or buccolingual direction, making the use of burs in this region incompatible (e.g., lower incisors or mesiobuccal roots of the upper molars).

Other limitations can be added (39-43). Patients with restricted mouth opening may hinder or even contraindicate guided access, especially in posterior teeth. CBCT exams that present image artifacts in the region can also limit the virtual planning and accuracy of the prototype guides for the technique.

However, the evolution of the technological tools used leads to expanding its indications and greater exploration of Digital Endodontics. A significant advance experienced in recent years refers to CBCT images. More modern appliances, and more innovative software with a greater number of resources $(39,40)$, have enabled a more faithful copy of the internal anatomy of the teeth, avoiding distortions that lead to inaccuracy and access errors. Thus, with the elimination of image artifacts arising from highdensity materials, guided access can be efficiently planned in the vast majority of indicated cases.

In this sense, technological advances open up other possibilities, such as the reduction of operative steps. With software capable of faithfully and accurately reconstructing anatomical structures (11) without distortions, intraoral scanning may soon be eliminated. The 3D reconstructions will be used as three-dimensional models of the arcade and converted into STL files. This reduction in operative steps is advantageous to both the patient (lower cost in preparing the guide) and the professional (lesser chance of distortions due to the elimination of steps).

Another aspect that has been evolving is also the tools used in the clinical stage of Guided Endodontics. The adaptation of drills from Implantology characterizes a significant limitation of the 
technique, which has been overcome with the development of instruments for Endodontics. The ultrasonic inserts developed for this purpose will represent a considerable advance in Guided Endodontics, with even more controlled wear (due to the smaller diameters of these inserts) and the possibility of more efficient irrigation during its use. However, the action of the ultrasonic insert can be restricted in guides with metal rings. Therefore, ultrasonic requires planning non-restrictive guides, with greater relief (offset) in the space the insert passes through the guide. In addition, non-restrictive guides require greater attention to perform the technique, allowing greater deviation from the worn path. It is currently indicating this type of guide for the following clinical situations: teeth with fragile roots that need a small amount of wear; or delimit osteotomy and apicectomy in endodontic surgeries.

Guided endodontics technology represents a new perspective for complex endodontic cases, which could lead to errors in surgical procedures using the conventional technique. It is a precise, effective and easy clinical application technique (41-44). It represents the incorporation of technological resources and digital planning in the life of the Endodontist, giving greater predictability to cases in which it is applied in clinical practice.

Furthermore, it requires minimal financial investment in the office since image capture equipment, virtual planning, and guides printing are part of the arsenal of digital planning centers. In addition, it takes a shorter number of clinical sessions, increasing patient comfort and reducing professional stress.

\section{Acknowledgements}

This study was supported in part by grants from the National Council for Scientific and Technological Development (CNPq grants 306682/2017-6 to C.E.).

\section{Resumo}

0 objetivo desta revisão é discutir o planejamento digital e o uso da tecnologia guiada em Endodontia. A complexidade e variabilidade da anatomia dos canais radiculares, em conjunto com o desafio no processo de sanificação e controle de micro-organismos representam fatores de risco ao fracasso após o tratamento dos canais radiculares infectados. 0 aprimoramento técnico-científico e os avanços tecnológicos tem possibilitado uma melhor previsibilidade de resultados nos procedimentos terapêuticos. 0 desenvolvimento de ferramentas de trabalho eficientes e modernas proporcionou tratamentos endodônticos seguros, com menor tempo clínico operacional e maior conforto ao paciente. A endodontia digital incorporou diferentes ferramentas e desenvolveu suas próprias, avançando ainda mais na resolução de casos complexos. A cópia fiel da anatomia interna proporcionada pelo avanço dos aparelhos e softwares de TCFC, associada aos recursos digitais de planejamento e impressão 3D possibilitaram o surgimento da endodontia guiada. Esta técnica é utilizada em diferentes etapas do tratamento endodôntico, com indicações específicas e maior previsibilidade de resultados. Este estudo revisou criticamente o potencial de aplicação clínica da técnica de acesso guiado, e os passos operatórios para sua realização de forma segura no manejo de casos endodônticos complexos. As principais indicações da Endodontia Guiada incluem o acesso a canais radiculares calcificados; as cirurgias parendodônticas em áreas de difícil acesso; a remoção de pinos de fibra de vidro; e o acesso a dentes com anomalias de desenvolvimento. Em sintese, a endodontia guiada é uma técnica precisa, eficaz e de fácil aplicação clínica. Esta técnica representa a incorporação dos recursos tecnológicos e planejamentos digitais do Endodontista, dando maior previsibilidade aos casos em que é aplicada na prática clínica. 


\section{References}

1. Pécora JD, Woelfel JB, Sousa-Neto MD. Morphologic study of the maxillary molars part I: external anatomy. Braz Dent J 1991;2:45-50.

2. Vertucci FJ. Root canal morphology and its relationship to endodontic procedure. Endod Topics $2005 ; 10: 3-29$.

3. Estrela C, Bueno MR, Couto GS, et al. Study of root canal anatomy in human permanent teeth in a subpopulation of Brazil's center region using cone-beam computed tomography - Part 1. Braz Dent J 2015;26:530-6.

4. Estrela $C$, Holland R, Estrela CR, Alencar AH, Sousa-Neto MD, Pécora JD. Characterization of successful root canal treatment. Braz Dent J 2014;25:3-11.

5. Estrela C, Decurcio DA, Rossi-Fedele G, Silva JA, Guedes OA, Borges ÁH. Root perforations: a review of diagnosis, prognosis and materials. Braz Oral Res 2018;32(Suppl. 1):e73.

6. Gavini G, Santos MD, Caldeira CL, Machado MEL, Freire LG, Iglecias EF, Peters OA, Candeiro GTM. Nickel-titanium instruments in endodontics: a concise review of the state of the art. Braz Oral Res 2018;32(suppl 1):e67.

7. Sousa-Neto MD, Silva-Sousa YCorrea, Mazzi-Chaves JF et al. Root canal preparation using microcomputed tomography analysis: a literature review. Braz Oral Res 2018;32(Suppl. 1):e66.

8. Morais AL, de Alencar AH, Estrela CR, Decurcio DA, Estrela C. Working Length Determination Using Cone-Beam Computed Tomography, Periapical Radiography and Electronic Apex Locator in Teeth with Apical Periodontitis: A Clinical Study. Iran Endod J 2016;11:164-8.

9. Decurcio DA, Rossi-Fedele G, Estrela C, Pulikkotil SJ, Nagendrababu V. Machine-assisted Agitation Reduces Postoperative Pain during Root Canal Treatment: A Systematic Review and Meta-analysis from Randomized Clinical Trials. J Endod 2019;45:387-393.

10. Jang SM, Kim E, Min KS. An Update on Endodontic Microsurgery of Mandibular Molars: A Focused Review. Medicina (Kaunas) 2021;57:270.

11. Bueno MR, Estrela C, Granjeiro JM, Estrela MRA, Azevedo BC, Diogenes A. Cone-beam computed tomography cinematic rendering: clinical, teaching and research applications. Braz Oral Res 2021;35:e024.

12. Bueno MR, Estrela C, Azevedo BC, Diogenes A. Development of a new cone-beam computed tomography software for endodontic diagnosis. Braz Dent J 2018;29:517-529.

13. Mazzi-Chaves JF, Camargo RV, Borges AF, Silva RG, Pauwels R, Silva-Sousa YTC, Sousa-Neto MD. Cone-Beam Computed Tomography in Endodontics-State of the Art. Curr Oral Health Rep 2021;8:9-22.

14. Bueno MR, Estrela C. Impact of a new cone beam computed tomography software on clinical decision-making in Endodontics. Dental Press Endod 2019;9:20-8.

15. Alauddin MS, Baharuddin AS, Mohd Ghazali MI. The Modern and Digital Transformation of Oral Health Care: A Mini Review. Healthcare (Basel) 2021;9:118.

16. Loureiro MAZ, Silva JA, Chaves GS, Capeletti LR, Estrela C, Decurcio DA. Guided endodontics: The impact of new technologies on complex case solution. Aust Endod J 2021. Epub ahead of print.

17. Park ME, Shin SY. Three-dimensional comparative study on the accuracy and reproducibility of dental casts fabricated by 3D printers. J Prosthet Dent 2018;119:861.e1-861.e7.

18. Silva EJNL, Barbosa AFA, Attademo RS, Lima CO, Decurcio DA, Pereira LAP. Endodontic accesses: what every endodontist should know. Dental Press Endod 2021;11:16-28.

19. Krastl G, Zehnder MS, Connert T, Weiger R, Kühl S. Guided Endodontics: a novel treatment approach for teeth with pulp canal calcification and apical pathology. Dent Traumatol 2016;32:240-246.

20. Connert T, Zehnder MS, Amato M, Weiger R, Kühl S, Krastl G. Microguided Endodontics: a method to achieve minimally invasive access cavity preparation and root canal location in mandibular incisors using a novel computer-guided technique. Int Endod J 2018;51:247-255.

21. Lara-Mendes STO, Barbosa CFM, Santa-Rosa CC, Machado VC. Guided Endodontic Access in Maxillary Molars Using Cone-beam Computed Tomography and Computer-aided Design/Computer-aided Manufacturing System: A Case Report. J Endod 2018;44:875-879.

22. Moreno-Rabié $C$, Torres $A$, Lambrechts $P$, Jacobs R. Clinical applications, accuracy and limitations of guided endodontics: a systematic review. Int Endod J 2020;53:214-231.

23. Connert T, Zehnder MS, Weiger R, KühI S, Krastl G. Microguided Endodontics: Accuracy of a Miniaturized Technique for Apically Extended Access Cavity Preparation in Anterior Teeth. J Endod 2017; 43:787-790. 
24. Connert T, Krug R, Eggmann F, Emsermann I, ElAyouti A, Weiger R, Kühl S, Krastl G. Guided Endodontics versus Conventional Access Cavity Preparation: A Comparative Study on Substance Loss Using 3-dimensional-printed Teeth. J Endod 2019;45:327-331.

25. Loureiro MAZ, Elias MRA, Capeletti LR, Silva JA, Siqueira PC, Chaves GS, Decurcio DA. Guided Endodontics: Volume of Dental Tissue Removed by Guided Access Cavity Preparation-An Ex Vivo Study. J Endod 2020;46:1907-1912.

26. Ahn SY, Kim NH, Kim S, Karabucak B, Kim E. Computer-aided Design/Computer-aided Manufacturing-guided Endodontic Surgery: Guided Osteotomy and Apex Localization in a Mandibular Molar with a Thick Buccal Bone Plate. J Endod 2018;44:665-670.

27. Ye S, Zhao S, Wang W, Jiang 0 , Yang X. A novel method for periapical microsurgery with the aid of 3D technology: a case report. BMC Oral Health 2018;18:85.

28. Benjamin G, Ather A, Bueno MR, Estrela C, Diogenes A. Preserving the Neurovascular Bundle in Targeted Endodontic Microsurgery: A Case Series. J Endod 2021;47:509-519.

29. Giacomino CM, Ray JJ, Wealleans JA. Targeted Endodontic Microsurgery: A Novel Approach to Anatomically Challenging Scenarios Using 3-dimensional-printed Guides and Trephine Burs-A Report of 3 Cases. J Endod 2018;44:671-677.

30. Maia LM, Bambirra Júnior W, Toubes KM, Moreira Júnior G, de Carvalho Machado V, Parpinelli $\mathrm{BC}$, Ribeiro Sobrinho AP. Endodontic guide for the conservative removal of a fiber-reinforced composite resin post. J Prosthet Dent 2021, in press.

31. Maia LM, Moreira Júnior $G$, Albuquerque RC, de Carvalho Machado V, da Silva NRFA, Hauss DD, da Silveira RR. Three-dimensional endodontic guide for adhesive fiber post removal: A dental technique. J Prosthet Dent 2019;121:387-390.

32. Perez $C$, Finelle $G$, Couvrechel $C$. Optimisation of a guided endodontics protocol for removal of fibre-reinforced posts. Aust Endod J 2020;46:107-114.

33. Schwindling FS, Tasaka A, Hilgenfeld T, Rammelsberg P, Zenthöfer A. Three-dimensional-guided removal and preparation of dental root posts-concept and feasibility. J Prosthodont Res 2020;64:104108.

34. Gomes MAB. Dentin loss in the access to the canal and removal of fiber posts for molar retreatment - Analysis by tomography and computed microtomography. PhD Thesis. Uberlândia: Dental School, Federal University of Uberlândia, 2020.

35. Mena-Álvarez J, Rico-Romano C, Lobo-Galindo AB, Zubizarreta-Macho Á. Endodontic treatment of dens evaginatus by performing a splint guided access cavity. J Esthet Restor Dent 2017;29:396-402.

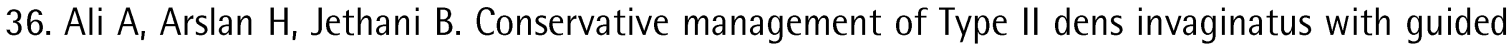
endodontic approach: A case series. J Conserv Dent 2019;22:503-508.

37. Zubizarreta-Macho Á, Valle Castaño S, Montiel-Company JM, Mena-Álvarez J. Effect of Computer-Aided Navigation Techniques on the Accuracy of Endodontic Access Cavities: A Systematic Review and Meta-Analysis. Biology 2021;10:212.

38. Zehnder MS, Connert T, Weiger R, Krastl G, Kühl S. Guided endodontics: accuracy of a novel method for guided access cavity preparation and root canal location. Int Endod J 2016;49:966-72.

39. Estrela C, Costa MVC, Bueno MR, Rabelo LEG, Decurcio DA, Silva JA, Estrela CRA. Potential of a New Cone-Beam CT Software for Blooming Artifact Reduction. Braz Dent J 2020;31:582-588.

40. Chaves GS, Estrela C, Silva FPY, Silva JA, Alencar AHG, Decurcio DA. Cone Beam Computed Tomography Assessment of the Volume of Dental Tissue Removed During Endodontic Access. Iran Endod J 2021;16:85-9.

41. Buchgreitz J, Buchgreitz M, Mortensen D, Bjørndal L. Guided access cavity preparation using cone-beam computed tomography and optical surface scans - an ex vivo study. Int Endod J 2016;49:7905 .

42. Buchgreitz J, Buchgreitz M, Bjørndal L. Guided Endodontics Modified for Treating Molars by Using an Intracoronal Guide Technique. J Endod 2019;45:818-823.

43. Kostunov J, Rammelsberg P, Klotz AL, Zenthöfer A, Schwindling FS. Minimization of Tooth Substance Removal in Normally Calcified Teeth Using Guided Endodontics: An In Vitro Pilot Study. J Endod 2021;47:286-290.

44. Torres A, Lerut K, Lambrechts P, Jacobs R. Guided Endodontics: Use of a Sleeveless Guide System on an Upper Premolar with Pulp Canal Obliteration and Apical Periodontitis. J Endod 2021;47:133-139. 